\title{
¿NUEVAS CRIADAS Y PORTERAS EN PARÍS?: REACTIVACIÓN DE LOS CAMPOS SOCIALES TRANSNACIONALES DE LA EMIGRACIÓN ESPAÑOLA TRAS LA CRISIS ECONÓMICA
}

\section{NEW MAIDS AND CARETAKERS IN PARIS?: THE REACTIVATION OF TRANSNATIONAL SOCIAL FIELDS OF SPANISH EMIGRATION FOLLOWING THE ECONOMIC CRISIS}

Resumen: Este artículo analiza la migración de mujeres españolas a Francia tras la crisis económica de 2008, desde la perspectiva de la reactivación de los campos sociales transnacionales, que se han ido construyendo históricamente entre ambos países. Muestra cómo los nichos ocupacionales generizados, que ocuparon las mujeres que migraron a París en los años 50-70 (bonnes à tout faire o criadas, empleadas de hogar, niñeras, porteras, limpiadoras) se están renovando, a raíz de la recesión, por la reactivación de los campos sociales transnacionales, construidos a través de las redes sociales tejidas por las diferentes corrientes migratorias. El texto señala como estos campos sociales transnacionales se cruzan con las cadenas globales de producción y reproducción, en términos de reorganización patriarcal del mercado de trabajo y de la fuerza laboral, de tal manera que la crisis económica ha traído consigo un reforzamiento de los canales tradicionales de reproducción social a través de los yacimientos laborales generizados.

Palabras clave: nueva emigración española; crisis económica; mujeres migrantes; trabajo doméstico y de cuidados; campos sociales transnacionales; Francia.

1 ESOMI, Facultade de Socioloxia, Universidade da Coruña. 


\begin{abstract}
This article analyses the migration of Spanish women to France following the 2008 economic crisis, considering the reactivation of the transnational social fields that have been built up between the two countries over the years. It reveals how the recession has led to a renewal of the gender-based labour niches filled by women emigrating to Paris in the period between 1950 and 1970 (bonnes à tout faire or maid, domestic workers, caretakers and cleaners), stemming from the reactivation of transnational fields built up through social networks woven by the various migratory trends. It provides an insight into the way these transnational fields are linked to global production and reproduction chains in terms of the patriarchal reorganisation of the labour market and workforce. It concludes that the economic crisis has reinforced traditional social reproduction channels rooted in gender-based sources of employment.
\end{abstract}

Key words: new Spanish emigration; economic crisis; female migrants; domestic and care work; transnational fields, France.

\title{
1. INTRODUCCIÓN: ESPAÑOLAS EN PARÍS
}

"Yo vine por la riada que hubo en Valencia en el año 57. Pasó por nosotros y a mi marido se le arruinó el negocio; tenía un negocio de artesanía de madera. El vino primero, entonces estábamos aún solteros, luego nos casamos y vine yo (...). En el metro de Belleville, en la rue Jean Jaurès, aquello era como un cuartel donde todos eran españoles. Estaba lleno de porteros y de chachas en habitaciones" (Española entrevistada en París en 1999: Oso, 2004:52-52)

Este testimonio pone de manifiesto la experiencia de mujeres, españolas en París, que migraron a la capital francesa durante finales de los años 50-principios de los 70 para trabajar como empleadas de hogar y porteras. Y que se ubicaron inicialmente en las chambres de bonnes, pequeñas habitaciones, reservadas para el servicio doméstico, en el sexto piso de los barrios parisinos. Su historia quedó anclada en la sociedad francesa bajo la figura de Conchita, esa criada, de fuerte acento ibérico y personalidad, que bien quedó reflejada en la filmografía española y francesa (Españolas en París, 
dirigida por Roberto Bodegas en 1971; Les Femmes du 6e étage, dirigida por Philippe Le Guay en 2011).

A finales de 2008 la riada volvió a Valencia, así como a otros lugares de España, bajo el formato de crisis financiera, que arrasó igualmente con negocios y con la economía de las familias, trayendo consigo otra migración. Este éxodo se ha presentado, en los medios de comunicación y en los debates políticos, como totalmente diferente a las anteriores corrientes migratorias a Europa (protagonizado por jóvenes, cualificados, que migran como ciudadanos de la UE), surgiendo discursos contrapuestos. Por un lado, como señalan Domingo y Blanes (2016) algunos interpretan este fenómeno como "nuevas movilidades" propias del "impulso aventurero" y emprendedor de los jóvenes españoles, hablando de "movilidad exterior" 2 . Por otro lado, se analizan los flujos de salida producto de la expulsión de población debido a las políticas de ajuste neoliberales, refiriéndose a los "expatriados", al "exilio económico"3. No obstante, en cualquiera de los dos casos, se hace hincapié en la "novedad", centrándose el discurso en la juventud y en la narrativa de la fuga de cerebros (Domingo y Blanes, 2016). Fijémonos en este otro testimonio:

"Llegué aquí a Paris y todo fue porque mi marido ya estaba aquí trabajando en un restaurante (...). Cuando él me trajo, vivíamos en la zona cinco, en las afueras de París. Nos alquilaron una cochera y dormíamos en el suelo (...) Y lo pasé muy mal, pero luego ya empecé a encontrar trabajo en una empresa española de limpieza" (Sagrario, entrevistada en París, 2016)

La historia de Sagrario parece sacada del mismo guion, de aquel que protagonizaron Ana Belén, Natalia Verbeke y Carmen Maura, pero también por Elena, Mercedes, Remedios... tantas mujeres que salieron de España en busca de una vida mejor hace 40 o 50 años y que tuve la oportunidad de entrevistar (ya mayores y cansadas), cuando recorrí, durante un intenso trabajo de campo, las cocinas, habitaciones de servicio y porterías del barrio burgués de París XVI (Oso, 2004). Pero Sagrario es una mujer joven, su rostro no refleja las intensas arrugas de toda una vida de sacrificio y trabajo, propia).

2 Por lo general desde sectores más proclives al gobierno (apreciación

3 Desde sectores más ligados a la oposición y los movimientos sociales (apreciación propia). 
como el de mis informantes de hace dos décadas. Hizo las maletas sólo hace cinco años, tras la crisis financiera, llegando a París en el año 2012. ¿Acaso su testimonio refleja una "nueva" migración? Aunque Sagrario haya salido del país con pasaporte europeo y, por lo tanto, con una serie de derechos que no tenían sus compatriotas en los 50-70 y disponga de un nivel de estudios más elevado (FP en integración social), su inserción laboral responde a la reactivación de los nichos laborales tradicionales de las mujeres españolas en la capital francesa.

Este artículo $^{4}$ tiene como objetivo analizar el vínculo que la denominada "nueva emigración española" tiene con las corrientes migratorias anteriores. Cuestiona, precisamente, la idea de la "novedad" y profundiza en una perspectiva de análisis que intenta relacionar la migración española a Europa, tras la crisis económica de 2008, desde la perspectiva de la reactivación de los campos sociales transnacionales, que se han ido construyendo entre ambos países a lo largo de la intensa historia de movilidades acontecida a ambos lados de los Pirineos. Y se centra en las migraciones protagonizadas por las mujeres, en el marco de la construcción de las cadenas globales de producción y reproducción (Oso y Ribas-Mateos, 2015).

El análisis parte, en primer lugar, del material empírico recopilado durante dos trabajos de campo cualitativos, realizados sobre la migración de mujeres españolas a París en los años 60-70 y sus descendientes (Oso, 2004; Oso (dir.), 2008). En segundo lugar, se han explotado los resultados de un nuevo trabajo de campo, que se llevó a cabo en octubre de 2016 con migrantes que salieron de España después de la crisis financiera de 2008, en el marco del cual se llevaron a cabo veinticuatro entrevistas en profundidad semi-dirigidas incluyendo tres informantes clave (Marea Granate, Federación de Asociaciones de Emigrantes Españoles en Francia - FACEFF, Consejería Laboral de la Embajada de España), siendo la mayoría de las personas entrevistadas mujeres (19). Del total de personas contactadas, trece estaban desarrollando un trabajo

4 Este artículo ha sido llevado a cabo en el marco de los siguientes proyectos: Oso (dir.) (2015-2019):

Género, movilidades cruzadas y dinámicas transnacionales,

Ministerio de Economía y Competitividad,

FEM2015-67164-R; Programa de Consolidación e Estructuración de Unidades de investigación competitivas do Sistema Universitario de Galicia (GRC2014/048; Oso, dir. 2014-2017). 
cualificado (aunque previamente algunas pasaron por el trabajo poco cualificado ${ }^{5}$ ) y once estaban empleados en un empleo poco cualificado (aunque disponían de estudios de EGB, secundaria, ciclos de FP e incluso, en algunos casos, de titulaciones universitarias) En este artículo explotaré el material de campo que hace referencia al empleo poco cualificado, centrándome en el sector de la limpieza y los cuidados personales.

En primer lugar, presentaré cómo ha abordado la producción científica española y europea esta migración surgida tras la crisis económica, poniendo de manifiesto el principal argumento de este artículo: una mirada centrada sobre la reactivación de la migración tradicional española a Francia, para el empleo en el mercado de trabajo poco cualificado y generizado. En segundo lugar, definiré el enfoque teórico basado en la construcción de campos sociales transnacionales y su articulación con las cadenas de producción y reproducción en el plano internacional. En tercer lugar, abordaré la construcción histórica de las corrientes de la migración española a Francia, intentando medir, con las limitaciones propias a las fuentes estadísticas disponibles, la magnitud y el perfil socioeconómico de los migrantes recientes, llegados tras la crisis económica de 2008. Por último, paso a analizar cómo se han ido tejiendo los campos sociales transnacionales a través de las redes sociales que vinculan las migraciones de los años 50-70 con la reciente migración. El artículo se centra en el segmento laboral de la limpieza y los cuidados personales y analiza la reactivación de estos nichos de empleo y en concreto del trabajo en tanto criada (bonne à tout faire), el pluriempleo en el sector de la limpieza y los cuidados y la portería. Estudia cómo a partir de las redes sociales, que contactan a la migración tradicional con los migrantes postcrisis, se han reactivado los campos sociales transnacionales generizados que nutren este segmento del mercado de trabajo. El texto concluye con un análisis que intenta poner de relieve la novedad de este estudio respecto a los trabajos previamente realizados en el contexto español.

5 Debido a la escasez de espacio no entraremos en el debate sobre la conceptualización trabajo cualificado/no cualificado, pero optamos por utilizar el término trabajo "poco cualificado" en lugar de "no cualificado". 


\section{MÁS ALLÁ DEL “BAILE DE CIFRAS”: UN ESTUDIO CUALITATIVO, CON UN ENFOQUE DE GÉNERO Y TRANSNACIONAL}

A partir del inicio de la crisis económica en 2008, con el cambio del ciclo migratorio español (Garrido, Miyar y Muñoz Comet, 2010; Aja, Arango y Oliver, 2012; Domingo, Sabater y Ortega, 2014; López-Sala y Oso, 2015, entre otros), la migración española comienza a resurgir del olvido, después de una intensa década de estudios y debates políticos centrados en la inmigración. Surgen, así, referencias a la Nueva Emigración Española, tanto en los medios de comunicación ${ }^{6}$, como en los trabajos de investigación (González-Ferrer, 2013; Domingo y Blanes, 2016). Esta problemática es igualmente foco de interés del debate político, tal y como señalamos anteriormente (Domingo y Blanes, 2016).

Los trabajos de corte académico, que empiezan a interesarse por esta nueva problemática de investigación, van a centrarse fundamentalmente en el "baile de las cifras": la dificultad de intentar medir desde el punto de vista estadístico esta realidad social, la debilidad de las fuentes de datos disponibles (tales como la Estadística de Variaciones Residenciales, la Estadística de Migraciones, PERE, CERE) y la elaboración de estimaciones (González-Ferrer, 2013; Navarrete, 2013; Domingo, Sabater y Ortega, 2014; Domingo y Blanes, 2016; Romero Valiente, 2017). El análisis cuantitativo, junto a los debates políticos, serán igualmente el principal foco de interés de la producción científica internacional que se ha interesado por la migración, surgida tras la crisis económica, del Sur al norte de Europa (Gropas y Triandaflyllidou, 2014; Lafleur y Stanek, 2017; Bermúdez and Brey, 2017; López-Sala, 2017; Glorius y DomínguezMújica, 2017; Glorius, 2017; Pumares, 2017). Son menos abundantes los estudios que, con una metodología cualitativa, han abordado esta realidad social, destacando algunas investigaciones que han llevado a cabo trabajo de campo fundamentalmente en Alemania y Reino Unido (Navarrete, 2013; Rubio, 2013; Cortés, Moncó y Betrisey, 2015; Dominguez-Mújica et al., 2016). No obstante, son pocos los

6 Véase, por ejemplo: El País, Los nuevos emigrantes españoles, 9 octubre 2013 http://elpais.com/elpais/2013/10/09/opinion/1381317179_264625.html

Hispanorama-549-02 La nueva emigración española, RTVE http://www. rtve.es/alacarta/audios/hispanorama/hispanorama-549-02-nueva-emigracionespanola/1153172/ 
trabajos sobre el caso francés, a excepción del estudio de Eremenko et al., (2017) que aborda la migración proveniente del Sur de Europa a este país tras la crisis financiera y que sigue centrándose en el análisis cuantitativo y el debate político.

Este artículo busca cubrir este vacío de la literatura. En primer lugar, pretende llevar a cabo un acercamiento a la migración española a Francia, tras la crisis económica, aportando a la producción científica datos sobre este contexto de acogida, que ha sido menos estudiado. Y lo hace con una aproximación cualitativa, intentando ir más allá de los trabajos centrados en el "baile de cifras" y en los debates políticos, siguiendo el enfoque que hemos desarrollado en el marco de proyectos de investigación recientes (Oso, Sáiz-López y Cortés, 2017). En segundo lugar, plantea un análisis desde la perspectiva de los campos sociales transnacionales, en la línea de otros trabajos llevados a cabo por la producción científica internacional (Levitt y Glick Schiller, 2006, entre otros). Cuestiona la idea de la "novedad", analizando la reciente corriente migratoria en su relación con las migraciones tradicionales del pasado y en concreto la desarrollada en los años 50-70. Saca a la luz cómo se está reproduciendo, de nuevo, una estratificación étnico-nacional del mercado de trabajo en París, a través de la llegada de los migrantes españoles tras la crisis económica, que se ubican algunos de ellos en los mismos puestos ocupados por sus compatriotas de los 50-70. Por último, el artículo se centra en las migraciones femeninas, lo cual supone igualmente una contribución a la producción científica española que ha abordado esta problemática de investigación, pudiendo sacar a la luz una perspectiva de análisis desde la segmentación generizada de los mercados de trabajo y la internacionalización de los trabajos de reproducción social. Veamos en qué fundamentamos esta aproximación teórica.

\section{LA CONSTRUCCIÓN GENERIZADA DE LOS CAMPOS SOCIALES TRANSNACIONALES}

En el ámbito de la literatura sobre migraciones internacionales, la perspectiva del transnacionalismo cuestiona las teorías más "tradicionales" de análisis de los movimientos migratorios (pullpush, binomio integración-asimilación, o la perspectiva que trata 
separadamente al país receptor y al emisor). Plantea que los contextos de origen y destino de los flujos migratorios, más allá de las fronteras geográficas, políticas y culturales, están conectados mediante las relaciones simultáneas y ramificadas que construyen y mantienen los migrantes (Glick Schiller, Basch and Szanton Blanc 1992; Vertovec, 2004). Saca a la luz el uso de algunos términos como el de campos sociales transnacionales, definido según Levitt y Glick Schiller "como un conjunto de múltiples redes entrelazadas de relaciones sociales, a través de las cuales se intercambian de manera desigual, se organizan y se transforman las ideas, las prácticas y los recursos. Los campos sociales son multidimensionales y engloban interacciones estructuradas de diferentes formas, profundidades y alcances, que se diferencian en la teoría social por los términos organización, institución, y movimiento social. Las fronteras nacionales no son necesariamente contiguas con las fronteras de los campos sociales. Los campos sociales nacionales son aquellos que permanecen dentro de las fronteras nacionales, mientras que los campos sociales transnacionales conectan a los actores a través de relaciones directas e indirectas vía fronteras" (Levitt y Glick Schiller, 2006:198).

Por otro lado, la literatura ha puesto de manifiesto que la ausencia de una redistribución sexual de los trabajos de reproducción social, en el marco de los hogares en el Norte, genera una demanda de mano de obra femenina inmigrante proveniente de países del Sur, una transferencia global de servicios reproductivos asociados al rol tradicional de las mujeres (cuidados, labores domésticas, actividades sexuales) (Truong Thanh-Dam, 1996; Ehrenreich y Hochschild, 2002). Según Sassen (2000) los sectores económicos en los cuales se ocupan las mujeres inmigrantes (servicio doméstico, limpieza, prostitución, etc), se están incorporando a la globalización a través de circuitos específicos que vinculan la demanda laboral y la oferta. A través de este tipo de circuitos se conectan trabajo, capital y cuidados desde el Norte Global para invertirse en múltiples formas en los hogares de origen de los migrantes en el Sur Global. Cadenas globales de producción y reproducción que se articulan junto a los movimientos poblacionales (Oso y Ribas-Mateos, 2015).

En este artículo partimos de este planteamiento teórico para estudiar la reciente migración española a Francia en el marco de la reactivación de los campos sociales transnacionales, que se han ido alimentando a través de las diferentes movilidades a un lado y otro 
de los Pirineos. Y busca analizar cómo estos campos se construyen, de forma generizada, sobre la base de la articulación de las cadenas de producción y reproducción en el plano internacional. Veamos, a continuación, como se han ido generando históricamente los campos migratorios entre España y Francia desde el siglo XX.

\section{LA CONSTRUCCIÓN HISTÓRICA DE LOS CAMPOS SOCIALES TRANSNACIONALES ENTRE ESPAÑA Y FRANCIA (S. XX-XXI)}

Los campos sociales transnacionales entre España y Francia se han desarrollado, a lo largo de los siglos XX y XXI, en sucesivas corrientes migratorias. Durante el periodo de entreguerras (años 20), el gobierno francés llevo a cabo una política de reclutamiento de trabajadores españoles para ocuparse en explotaciones agrícolas y la producción industrial, ascendiendo a 351.000 los españoles censados en el país vecino en 1931 (Daguet, 1995; Lillo, 2004). A esta corriente le siguió el exilio republicano, que se inició en 1936 y se agudizó con la victoria del régimen de Franco en 1939, alcanzando los desplazados tras la guerra civil a 500.000 personas (DreyfusArmand, 2000). A mediados de los cincuenta, el gobierno francés promovió la llegada de trabajadores extranjeros, ante la demanda del mercado de trabajo durante la fase de crecimiento económico. Así, en 1968 los españoles censados alcanzaron 607.184, configurándose en el primer país de origen de la inmigración en Francia. Si las primeras corrientes migratorias estuvieron fundamentalmente protagonizadas por hombres, esta última tuvo un componente femenino mayor, debido a la existencia de una demanda de empleadas de hogar característica de la migración española a París de los sesenta/setenta, consolidándose la figura de la Bonne espagnole o criada española en la sociedad francesa (Taboada-Leonetti, 1987; Oso, 2004; Tur, 2014).

A partir del cierre de fronteras en Europa, tras la crisis del petróleo, se observa un descenso progresivo de la comunidad española censada en Francia, reduciéndose en el censo de población de 1999 a los niveles observados a principios del siglo XX. Este censo además reflejaba ya una población envejecida, característica de una corriente madura $(46 \%$ de los censados tenían 60 o más 
años). No obstante, las movilidades siguieron desarrollándose de un lado a otro de los Pirineos. En efecto, tras el ingreso de España a la Unión Europea, aunque en términos globales la migración española a Francia haya disminuido, se constata "un incremento lineal en la migración de españoles cualificados, que sustituye a la emigración de trabajadores no cualificados" mayoritaria anteriormente (Alaminos y Santacreu, 2008:204). Además, los campos sociales transnacionales entre España y Francia se alimentaron también por movimientos desde el país galo a territorio español, a través de la migración de retorno de emigrantes españoles, pero igualmente de los movimientos protagonizados por franceses hacia España, a lo cual hay que añadir la migración circular y fronteriza.

La movilidad desde España a Francia se reactiva tras la crisis económica de 2008. Sin entrar en los debates sobre las dificultades de medir este fenómeno podemos avanzar estimaciones sobre la evolución de los flujos más recientes. Cabe señalar que en este artículo me voy a centrar en analizar la migración de españoles nacidos en España y no la de inmigrantes naturalizados españoles, debido a que esta última responde a características específicas, que dejo para otros trabajos ${ }^{7}$.

Las estimaciones llevadas a cabo por Domingo y Blanes, a partir de la Estadística de Variaciones Residenciales (EVR) sacan a la luz que Francia representa el segundo país de destino receptor de los flujos migratorios de españoles nacidos en España que se desarrollan tras la crisis económica, alcanzando 9.162 salidas de 2009-2011 y 14.878 de 2012-2014, lo cual supone respectivamente

7 Las principales fuentes para el estudio de los flujos de emigración disponibles en España (Estadística e Variaciones Residenciales - EVR, Estadística de Migraciones - EM, Padrón de Españoles Residentes en el Extranjero-PERE y Censo Electoral de Residentes Ausentes-CERA), se basan en las inscripciones consulares, altas y bajas del PMH. Estas fuentes adolecen de un importante sub-registro, tal y como ha sacado a la luz la literatura (González-Ferrer, 2013; Domingo y Blanes, 2016; Romero Valiente, 2017). La EVR también puede presentar sobre-registro, puesto que contabiliza variaciones residenciales y no personas, por lo que una misma persona puede realizar más de una variación residencial (OPAM, 2013).

Estos datos permiten diferenciar a los españoles nacidos en España (de los cuales nos vamos a ocupar en este artículo) de aquellos que han nacido en el extranjero (de origen inmigrante); si bien, no posibilitan identificar a los hijos de inmigrantes que han nacido en España (hijos por ejemplo de inmigrantes ecuatorianos, marroquíes, etc). 
un $9,4 \%$ y un $11 \%$ del total de salidas, para cada uno de estos dos periodos analizados (Domingo y Blanes, 2016). La explotación de la Estadística de Migraciones (EM) que he llevado a cabo personalmente muestra, no obstante, que en 2014 y 2015 Alemania sobrepasa, por poco, a Francia como segundo país de acogida de los flujos migratorios de españoles nacidos en España (11,3\% y 10,7\% salidas respectivamente). En los flujos de migración a Francia, la presencia de las mujeres es elevada, puesto que sobrepasa a la de los hombres, alcanzando entre un 52 y un 53\% de las salidas entre 20082015. En lo que respecta al stock de españoles nacidos en España, registrado en el PERE, los datos ponen de relieve un incremento de la presencia de migrantes en Francia desde la llegada de la crisis económica, siendo también mayor el porcentaje de mujeres en esta fuente estadística.

\section{TABLA 1}

STOCK DE ESPAÑOLES, NACIDOS EN ESPAÑA, RESIDENTES EN FRANCIA

\begin{tabular}{|l|c|c|c|}
\hline & Ambos Sexos & Variación interanual & \% Mujeres \\
\hline 2009 & 115.216 & & 51,7 \\
\hline 2010 & 114.160 & -1.056 & 51,9 \\
\hline 2011 & 115.180 & 1.020 & 52,1 \\
\hline 2012 & 116.096 & 916 & 52,2 \\
\hline 2013 & 118.072 & 1.976 & 52,4 \\
\hline 2014 & 121.287 & 3.215 & 52,6 \\
\hline 2015 & 124.153 & 2.866 & 52,7 \\
\hline 2016 & 127.557 & 3.404 & 52,8 \\
\hline 2017 & 131.395 & 3.838 & 52,9 \\
\hline
\end{tabular}

Fuente: Estadística del Padrón de Españoles Residentes en el Extranjero (PERE), INE.

Elaboración propia. Datos a 1-1-2017.

Por su parte, los datos explotados por Eremenko et al. (2017) (censos de población en Francia), aunque cuentan igualmente con un importante sub-registro, permiten sacar a la luz algunos indicios 
sobre el perfil socioeconómico de los migrantes recientes (llegados en los últimos 5 años y de 15 o más años), lo cual no es posible identificar a partir de las estadísticas españolas. Para estas autoras, el nivel educativo de los migrantes españoles recientes ha descendido en los últimos años (de 2006 a 2011). Así, si en 2006 la mayoría de los migrantes recientes disponía de un diploma de estudios terciarios (62,5\%), en 2011 disminuye el porcentaje de los más cualificados a un $59 \%$, aumentando la proporción de los que tienen estudios por debajo del nivel de secundaria (que pasan de representar un $12,8 \%$ en 2006 a alcanzar un $16,8 \%$ en 2011). Este descenso del nivel educativo es paralelo con un incremento de la proporción de los migrantes españoles recientes en ocupaciones de baja cualificación. Así, mientras que en 2006 los migrantes españoles que se empleaban en puestos de "bajo nivel" suponían un 15\%, en 2011 este grupo aumenta en cuatro puntos porcentuales, pasando a representar un $19,3 \%$ de los migrantes españoles recientes ocupados en el mercado de trabajo francés ${ }^{8}$. Estas estadísticas ponen de relieve que la crisis económica ha acelerado la migración de españoles en Francia; si bien, los datos de Eremenko et al. (2017) no se corresponden con el imaginario que asocia esta migración con la salida exclusiva de jóvenes cualificados, sino que paradójicamente lo que parece haberse incrementado porcentualmente es la parte menos cualificada y correspondiente a los sectores ocupacionales más bajos.

Como vemos, a raíz de la crisis económica, se ha incrementado la migración de jóvenes españoles cualificados para insertarse al mercado de trabajo, así como la de estudiantes; si bien, esta corriente, tal y como sacaron a la luz Alaminos y Santascreu (2008), ya se estaba dando antes de la crisis económica, por lo que no se trata de un fenómeno completamente "nuevo". Por otro lado, la recesión ha reactivado la migración no cualificada. Y es precisamente esta idea de continuidad, frente a la imagen de la "novedad", que se ha transmitido en los medios de comunicación y en el discurso político, lo que queremos poner de relieve en este artículo. Estas corrientes se han reactivado por medio de las redes sociales que se construyen

8 Estas autoras diferencian entre ocupaciones de bajo, medio y alto nivel. "Low-level occupations refer to unskilled employees and labourers, including agricultural workers. Mid-level occupations refer to intermediate professions, skilled employees, labourers and tradesman. High-level occupations refer to directors of companies of 10 or more employees and executives" (Eremenko et al., 2017:133) 
a un lado y otro de los Pirineos, a través del tejido social que la propia historia migratoria ha ido generando. A continuación, nos centraremos en sacar a luz la revitalización de estos campos sociales transnacionales, a partir del ejemplo del segmento laboral de la limpieza y los cuidados personales.

\section{REDES SOCIALES QUE TEJEN LOS CAMPOS SOCIALES TRANSNACIONALES: LA REACTIVACIÓN DEL SEGMENTO LABORAL DE LA LIMPIEZA Y LOS CUIDADOS PERSONALES}

Los datos del trabajo de campo revelan que hay una red migratoria que está apoyando a la nueva corriente migratoria de españoles en Francia y que está sustentada en la migración económica de finales de los 50 y principios de los 70, que aún cuenta con una presencia relevante en Francia, desde el punto de vista cuantitativo y asociativo. Ya envejecida, ha dado lugar a segundas y terceras generaciones (Oso, 2008) y supone un nódulo de contactos que está siendo revitalizado, tras la crisis económica, por los migrantes recientes. Esta red sirve de estímulo para emigrar y aporta los recursos para la llegada y primera instalación en París, así como para la inserción al mercado de trabajo, por lo general en yacimientos de empleo poco cualificados que han ocupado tradicionalmente los españoles en la capital francesa y que están fuertemente generizados.

\subsection{Las criadas o bonnes à tout faire}

En el caso de las mujeres, son varios los yacimientos laborales de empleo que ocupó la migración económica tradicional de los años 50-70. El primero de ellos fue el de las empleadas de hogar o bonnes à tout faire. Este tipo de trabajo, generalmente presente en los barrios burgueses de la capital parisina, fue realizado por las españolas, fundamentalmente al inicio del ciclo migratorio, como una puerta de entrada a la capital francesa. Los edificios de construcción Haussmann permitían a las migrantes disponer de una habitación propia, la chambre de bonne (denominada en la jerga española de la migración, la chambra) en el último piso de los edificios, independiente, a la cual se accedía por una escalera 
de servicio. Pequeños cubículos en los que dormían las criadas, que compartían el baño común situado en el pasillo de la sexta planta. Con el paso de los años, la burguesía empezó a sustituir la figura de la bonne à tout faire por la de la señora de la limpieza; si bien, en las familias de "alta alcurnia" se mantuvo el servicio. Algunas de las mujeres siguieron empleadas como internas pudiendo disponer de varias habitaciones en la sexta planta en la cual vivían con su familia; otras, pasaron a buscar una residencia fuera del trabajo, manteniendo el empleo de bonne, pero sin dormir en el mismo edificio. Este nicho de empleo se sustentó tradicionalmente sobre las redes sociales comunitarias de las mujeres españolas; es decir, que cuando una empleada cambiaba de casa o se jubilaba, recomendaba a otra compatriota.

No obstante, el trabajo de campo que llevé a cabo en París en el año 99-2000 (Oso, 2004), así como el posterior estudio sobre los hijos de españoles en Francia (Oso, 2008), ponían de relieve que este nicho de empleo ya no estaba reproduciéndose entre la comunidad española, debido a que desde mediados de los setenta se había frenado la migración no cualificada y que los hijos de los migrantes habían accedido a un nivel de estudios medio, incluso alto, que permitía una inserción cualificada sobre el mercado de trabajo francés. Las madres españolas lucharon para que sus hijas no fuesen criadas, ni porteras y saliesen del segmento de la limpieza. Así, en los barrios burgueses parisinos, como París XVI, otras migrantes estaban empezando a copar este segmento del mercado de trabajo (filipinas, latinoamericanas, etc.) (Oso, 2004; Oso, 2008).

La llegada de la crisis económica revitaliza la red de la migración tradicional y este yacimiento de empleo a través de las nuevas llegadas, de manera que los protagonistas del reciente éxodo también vendrá a desempolvar los trapos y la escoba. El envejecimiento de la población que migró a París en los 50-70 estimula estas cadenas migratorias, al permitir el reemplazo en los puestos, por parte de las personas más jóvenes que migran tras la crisis de 2008 .

Retomamos la historia de Sagrario para ilustrar cómo se reactivan estos campos sociales transnacionales. Nuestra informante es de un pueblo de Valencia, Oliva. Este pueblo, así como otras localidades de los alrededores, fueron protagonistas de la fuerte corriente migratoria que tuvo lugar en los años 50-70 hacia París. Sagrario consigue un empleo como bonne à tout faire gracias a una señora de su pueblo que la recomienda para el puesto. 
"En este edificio (tiene cuatro plantas), todos los que trabajamos somos españoles. Yo trabajo aquí sola. En la planta de arriba trabaja una chica y su esposo. Está también la portera, todos somos españoles. Sí, porque los propietarios son de origen hispano. Cada persona se ocupa de una casa y de atender a los señores (...) Antiguamente venían mucho los españoles aquí para servir a los señores. Y la gente como nosotros, los trabajadores, dormíamos, por ejemplo, en el sixième étage. Continúa igual, pero eso, como que se había ido perdiendo por el cambio de vida, no sé, por las nuevas generaciones (...) Y ya los señores han ido falleciendo y los hijos es otra cosa ¿sabes? Se ha ido perdiendo. Pero gracias a la señora que se ha jubilado en la planta de arriba... Es de mi pueblo y me conoce desde siempre. Sabía que yo estaba aquí (se refiere a París) y cuando se jubiló, arriba ha venido un familiar de ella, pero se jubilaba también la señora de aquí y me han puesto a mí en esta plaza" (Sagrario, Valencia, empleada de hogar)

Sagrario se ocupa de la casa, vive con su marido y su hija en las habitaciones de servicio de la sexta planta. Es originaria del medio rural, sus padres no tienen estudios, fueron siempre trabajadores poco cualificados. Pero en su familia hubo una fuerte movilidad social intergeneracional: "Nosotros somos seis hermanos, todos tienen su carrera, su buena posición". Sagrario, a diferencia de sus compatriotas de los años 50-70, tiene un nivel de estudios medio, hizo un ciclo de FP en integración social, pero la crisis económica la llevó a migrar. A diferencia de los migrantes de los 50-70 dispone de pasaporte europeo y no tiene problemas para poder trabajar legalmente en Francia. No obstante, tuvo que recurrir a la ayuda de su tía, instalada en la capital francesa, emigrante de antaño, para amortiguar los golpes de aterrizar en París y sobre todo para buscar empleo y "coger lo que hay".

"Yo no sé con cuántos españoles habrás hablado, pero cuando vienes aquí, necesitas tanto el trabajo, que cualquier cosa decente que te den, la coges. No te hablo de la época de mi tía, te hablo de la época de ahora. Porque yo conozco gente, pues qué te diré: profesor, periodista, veterinario. Y estaban trabajando en un Mc Donald. Quiero decir, que te coges a lo que hay. Pero porque en España la situación es peor, aunque estés trabajando en un Mac Donald, aquí lo bueno es que te respetan tus horas, te pagan el salario cuando llega el final de mes, tienes tus condiciones de trabajo. Y además, que como estás aquí, y necesitas trabajar, a lo que te salga (...) Cuando vienes aquí, de verdad, sufres mucho. Si 
vienes con un bolsillo así (se refiere a un bolsillo grande, a tener dinero), que te puedes pagar tu apartamento, si tienes algún padrino que te bautice..., pero como vengas sin nada y a buscarte la vida, se pasa muy mal" (Sagrario, Valencia, empleada de hogar)

No obstante, la revitalización de los campos sociales transnacionales no se realiza solo con "nuevos candidatos a la migración", sino que está compuesta, a menudo, por hijos de emigrantes de los años 50-70, que nacieron y se criaron en París, regresaron a España y, ante la crisis económica, despliegan su mirada y vuelven a Francia. En este caso se trata de una historia de idas y vueltas, de un vaivén transnacional, en el cual las diferentes generaciones van circulando por un espacio social u otro, o más bien por ese campo social transnacional, que se alimenta no sólo de las redes sociales, sino igualmente del "savoir faire" que disponen aquellos que se criaron en las chambras o las porterías, incluyendo el conocimiento del idioma y haber recibido una educación francesa. Es el caso de Ana, que trabaja como empleada de hogar, junto a su marido que ejerce de chofer. Sus padres emigraron a Francia en los años sesenta, la madre tenía una portería en París XVI. Las hijas nacieron en la ciudad de la luz, donde se criaron hasta que Ana tenía dieciocho años y el matrimonio decide regresar a España. No obstante, con cuarenta y dos años, Ana vuelve a París, debido a la crisis económica. Sin estudios, Ana trabajaba en Valencia recogiendo naranja y haciendo horas de limpieza; el marido era camionero y se quedó en paro tras la recesión. Una allegada a la familia le propone: "mira, chica: yo, si quieres, como te conozco de pequeña y todo, si quieres venirte a París, yo te dejo este puesto".

La Iglesia española de la Rue de la Pompe, situada en el barrio de París XVI y que antaño era uno de los principales lugares de búsqueda de empleo para las mujeres españolas, dejó de ser transitada por compatriotas originarias de España, para pasar a ser un lugar de acogida de migrantes latinoamericanas, recién llegadas a Paris en búsqueda de empleo, que fueron sustituyendo a las españolas (Moré Corral, 2015). No obstante, son varios los testimonios que ponen de relieve cómo se está reactivando este canal de búsqueda de empleo también para las mujeres, nacidas en España, que emigran a partir de 2008. Así, por ejemplo, la madre de Natalia, cuya trayectoria explicaremos con detalle más adelante, solía aconsejarle: Mi madre me decía ¿Y por qué no vas a la Iglesia 
española a buscar faena? Porque cuando yo estuve en París, yo fui a buscar faena alli (...) Cuando nosotras vinimos en el 2013 habia mucha gente española que se dirigía a la iglesia española a buscar. Una amiga nuestra de Sevilla fue a buscar trabajo alli".

\subsection{El pluriempleo: cuidados, limpieza y burones}

La segunda modalidad de empleo que ocuparon las mujeres españolas que migraron a Paris en los 50-70 fue el pluriempleo, que permitía ahorrar una importante cantidad de dinero, limpiando o cuidando niños en varias casas y complementando con la limpieza de oficinas o lo que se denominó en la jerga de la migración, los burones (de bureaux en francés). Este tipo de trabajo se desarrolló en barrios menos burgueses de la capital francesa, como en París XV, donde las españolas trabajaban para familias de clase media o media-alta por horas (Oso, 2004). Y está siendo igualmente revitalizado a través de las migrantes recién llegadas. De hecho, Sagrario inicia su periplo laboral en Paris trabajando en una casa cuidando niños, gracias a un contacto que le pasa su tía y completando este empleo con limpieza de oficinas.

"Yo tengo una tía que vive aquí, que ya está jubilada, entonces empecé a frecuentarla, ella me ayudó a buscar trabajo para cuidar niños. Y ahí cuando empecé a cuidar niños ahí se me abrieron todos los caminos. Ella vino con dieciocho años, hace cincuenta años. También estuvo sirviendo. Hizo de todo, mi tía, menos cosas malas (...) Y gracias a mi tía, ella vivía en París XV y ahí hay mucho trabajo de cuidar niños que se gana muy bien la vida. Y entonces mi tía iba a una fisioterapeuta y le comentó: mira busco una chica para cuidar a mi hijo. Fui, pasé la entrevista y he estado casi tres años con esa familia. Y ellos me ayudaron a buscar un piso (Sagrario, Valencia, empleada de hogar")

La historia de Inés es similar a la de Sagrario. También oriunda de un pueblo de Valencia, su madre estuvo en París sirviendo en una casa, hizo amistad con otra mujer del mismo pueblo con quien mantuvo el vínculo después de regresar a Valencia. Inés estudió unos años de FP, aunque no consiguió acabar el ciclo formativo, estuvo trabajando en un laboratorio de una empresa de cementos. Compró un piso, pero, con la llegada de la crisis económica a España, no 
podía pagar la hipoteca. La amiga de su madre, afincada en París, le propuso: "que se venga tu hija, yo la tengo unos días, yo le busco limpieza". Inés trabaja en una casa cuidando a personas mayores, empleo que combina limpiando y sirviendo en una casa de una familia burguesa parisina, vive en un apartamento de alquiler de diez metros cuadrados.

\subsection{La portería: ganarse la lotería}

Otro de los segmentos del mercado de trabajo que ocuparon las mujeres españolas en los años 50-70 fue la portería, lo cual suponía una estrategia laboral muy óptima cuando se casaban y tenían hijos, en la medida en que podían disfrutar de una vivienda gratis, recibir un sueldo y, al mismo tiempo, poder ocuparse de los hijos. Así, muchas de las españolas que emigraron a Paris durante los 50-70 fueron bajando de las chambras a las porterías, con la llegada de los descendientes. Con el declive de la migración española a finales de los 70, muchas porterías de los barrios burgueses parisinos pasaron a manos de mujeres portuguesas y de otros orígenes, que fueron sustituyendo a las españolas (Oso, 2004). No obstante, los emigrantes postcrisis van a encontrar igualmente un lugar en las porterías. Las jubilaciones de las compatriotas españolas van a posibilitar a los recién llegados encontrar refugio como conserjes. Es el caso de Natalia, también valenciana y sobrina de porteras.

"A mí siempre me gustó París, yo empiezo a venir aquí con catorce años, porque mis tías trabajaban en una portería. Y vengo ya muchas veces de vacaciones (...) Yo salgo de un pueblo pequeño de dos mil habitantes de Valencia, en el que todo el mundo tiene a alguien conocido que ha venido a trabajar a París. Dentro de mi pueblo, la emigración que vino a París, el que no tiene una familia, tiene un vecino o tiene a alguien. Era lo típico de aquella época, que alguien del pueblo, se iba (...). Y que, de un pueblecito profundo, lleno de naranjos, me trajeran aquí... aquello para mí fue... La idea que yo siempre había tenido era de vivir o venir a temporadas aquí. Yo se lo propongo, viviendo mis tías aún aquí, pero mis tías no están por la labor. A ellas no les faltaba mucho para jubilarse, entonces la idea de que yo pudiera venir, que fuera yo la que me quedara y ellas se vinieran a Valencia, pues no les hacía mucha gracia. Pasan los años y conozco a Carmen, venimos 
las dos aquí de turismo, fue nuestra primera luna de miel, luego ya nos casamos... Y sobre todo fue culpa de la crisis en España. Nos quedamos sin trabajo. Nos vinimos a París a pasar la nochevieja del 2012 al 2013. Y pensamos: ¿por qué no nos venimos aquí a París a vivir?" (Natalia, Valencia, portería)

Natalia no disponía ya de contactos directos cuando decidió emigrar a París, sus tías ya habían regresado hace muchos años a Valencia y habían fallecido. No obstante, el haber tenido contacto con ellas y haber pasado muchos veranos en París le habían dotado de un "savoir faire", de unos conocimientos sobre el trabajo en las porterías, por lo que empezó a buscar en el sector.

De oficio carnicera, sabía que en París esta profesión está fundamentalmente en manos de hombres, muchos de ellos de origen magrebí, por lo que no insistió mucho en encontrar empleo en su sector. Al conocer, a través de los recuerdos de su infancia, la opción de la portería, empieza a echar currículums en las empresas que mueven las ofertas para este tipo de empleo. Por medio de la Casa de Valencia le sale la posibilidad de quedarse con la portería de una conocida asturiana que iba jubilarse. Siguiendo la tradición de antaño, aquella que regía informalmente los canales de búsqueda de empleo en los años 50-70, y que quedó reflejada en la película Les Femmes du Sixième Etage, a Natalia le piden mil euros por la portería, por hacer las veces de recomendarla de cara a la entrevista con la comunidad de vecinos. A lo cual nuestra informante no accede. Vuelve a mandar el currículum hasta que una empresa intermediaria de colocación le propone una entrevista para reemplazar a una compatriota española que iba a jubilarse. Consciente de la importancia de caerle bien a la portera salmantina, Natalia se presenta en la portería a hablar con ella, consigue ganarse su confianza y que la avale. Nuestra informante siente en ese momento que "ha ganado la lotería". La portería le garantiza una jubilación tranquila, es un trabajo cómodo, que no tiene un desgaste físico tan grande como el de carnicera. Y supone igualmente un punto de apoyo para que su compañera Carmen, cansada de trabajar con contratos temporales en hoteles de la cadena Meliá, decida dejar la empresa española y buscara un empleo más acorde a su nivel de estudios (FP en integración social). Así consigue un trabajo como auxiliar de vida escolar (apoyo a estudiantes discapacitados) en un instituto de secundaria. La portería es, como vemos, el salto a la movilidad laboral de Carmen. 
El no pagar vivienda, en una ciudad como París, y disponer de un trabajo a tiempo parcial, relajado, permite, además, a Natalia poder coger empleos suplementarios (cuidando niños, animales domésticos, limpiando eventualmente en casas, sustituciones temporales en otras porterías) de cara a incrementar sus ingresos mensuales. La portería abre claramente las redes de contacto entre el vecindario, las otras porteras del barrio, ampliando la fuente de ofertas de empleo complementarias.

La portería, tal y como la conciben nuestras informantes, sirve igualmente como una puerta de entrada para otros potenciales migrantes: "se lo decimos a la gente (...) esto es una puerta de entrada, si alguien necesita venir para buscar trabajo en Francia, de alguna manera somos una entrada" (Carmen, Valencia, auxiliar de vida escolar). Una vía de escape para la sobrina de Natalia, por ejemplo: "si ese es el futuro que tiene, irse a la casa del pueblo para cuidar a su madre y vivir de la pensión de tu madre que está en una silla de ruedas, que es como un bebé de dos años... Si ese es el futuro que tiene, para eso me la traigo aquí, que siga estudiando, si tenemos una portería más grande o que busque trabajo como auxiliar de vida escolar, como ella, porque aquí hay más oportunidades (...) para mí esto es una puerta" (Natalia, Valencia, portería).

Este último testimonio pone de relieve cómo, en ocasiones, la migración femenina también puede constituirse en una reacción y resistencia a la imposición de roles tradicionales de género que la crisis económica ha reactivado. Así, la migración puede configurarse en una estrategia para luchar contra un futuro, sin trabajo, centrado en encargarse de las personas mayores y enfermas de las familias y vivir de las pensiones y ayudas. Este es el caso de la sobrina de Natalia, abocada a cuidar de su madre enferma ante el bloqueo de su futuro profesional en España. El testimonio de nuestra informante revela un rechazo a que su sobrina acepte esta imposición de cuidados familiares, que se ha visto reactivada para las nuevas generaciones de mujeres españolas, ante las dificultades de inserción laboral tras la crisis económica.

Ya en su día Natalia vio en la portería de sus tías una opción de futuro, a la cual tuvo que recurrir ya en avanzada edad, cuando la recesión azotó su contexto económico y social en Valencia. Y ahora vuelve la mirada hacia su sobrina y le ofrece esa misma oportunidad, como una salida a la situación de estancamiento que vive la juventud española. 
El testimonio de Natalia también pone de relieve cómo los campos sociales transnacionales no sólo son útiles para los migrantes poco cualificados, sino que también pueden utilizarse por migrantes cualificados para su inserción inicial en Francia. No obstante, la construcción de los campos sociales transnacionales de la migración cualificada, su activación, su cruce o no con otros campos migratorios, es una historia de la cual me ocuparé en futuros trabajos. En este artículo he querido centrarme en el perfil socioeconómico del migrante que ha sido más invisible en el debate político y menos abordado por la literatura académica. $\mathrm{He}$ buscado cuestionar la idea de la "novedad" de la migración surgida tras la crisis financiera en España, planteando un análisis centrado en las continuidades y en la reactivación de los campos sociales trasnacionales. Y, sobre todo, en el cruce de la corriente migratoria femenina para el trabajo en el sector de la limpieza/cuidados de los años 60/70 y la corriente actual de mujeres para el mismo tipo de empleos, tras la crisis económica del 2008.

\section{CONCLUSIONES}

Como vemos, los nichos laborales generizados, que ocuparon las mujeres que emigraron a París en los años 50-70 se están renovando con la llegada de españoles a Francia a partir de 2008. Trabajadores poco cualificados, los protagonistas de la historia que hemos contado en estas páginas responden a un perfil socioeconómico muy diferente al que reflejan los medios de comunicación: bonnes à tout faire o criadas, empleadas de hogar, niñeras, porteras, limpiadoras. Una migración que está permitiendo el reemplazo laboral (ya estudiado en otras corrientes migratorias, como la de México-EEUU, por ejemplo) y la reactivación de la estratificación étnico-nacional en el mercado de trabajo parisino.

En este artículo, hemos visto como el acceso a la capital francesa y al mercado de trabajo de la corriente migratoria impulsada tras la crisis de 2008, se ha visto facilitado por la reactivación de los campos sociales transnacionales. Y sobre todo por la migración española a Francia de los años 50-70. Estos campos se han alimentado por las redes sociales que se han ido tejiendo a partir de las diferentes corrientes migratorias. Incluyen, tanto a hijos de migrantes que nacieron en 
París, regresaron a España en los años setenta u ochenta y vuelven a migrar a Francia tras la crisis económica de 2008, como a familiares, amistades, vecinos de los pueblos que protagonizaron históricamente una fuerte migración. Los campos sociales transnacionales se construyen no sólo a través de las redes personales de contacto, sino también mediante un "savoir faire" que incluye conocimientos del idioma, de la cultura y sociedad francesa, de los recursos que pueden activarse en una situación de migración (ayudas sociales, etc), siendo clave a la hora de proporcionar una primera inserción (vivienda y búsqueda de empleo) a la sociedad de destino.

El texto pone igualmente de relieve como estos campos sociales transnacionales se cruzan igualmente con las cadenas globales de producción y reproducción, generándose una reconfiguración de fuerzas compleja. Así, si en los años 50-70 las mujeres españolas emigraban a Francia como parte de la articulación de las cadenas de producción y reproducción del Sur al Norte global, en los años 8090 España empieza a configurarse en un polo del Norte, recibiendo mujeres inmigrantes para el trabajo de limpieza y cuidados personales. La crisis económica despierta, de nuevo, el papel de España como Sur global, respecto a sus vecinos del Norte europeos, reactivándose el ejército español armado con balletas y escobas para trabajar en el sector de la limpieza y los cuidados personales. Un segmento del mercado laboral, que se alimenta fundamentalmente de las redes informales de contacto que se construyen, de forma generizada y etnificada, en los campos sociales transnacionales. El sistema de reclutamiento vía recomendación, para las empleadas de hogar y las porteras, es la clave de esta reactivación del mercado de trabajo, en una situación de envejecimiento de la mano de obra migrada en los 50-70.

En definitiva, en términos de reorganización patriarcal del mercado de trabajo y de la fuerza laboral, la crisis económica ha traído consigo un reforzamiento de los canales tradicionales de reproducción social a través de los yacimientos laborales generizados y etnificados.

\section{BIBLIOGRAFÍA}

Aja, E.; Arango, J. y Oliver, J. (2012) (eds.): Inmigración y crisis. Entre la continuidad y el cambio. Barcelona, CIDOB. 
Bermudez, A. y Brey, E. (2017): «Is Spain Becoming a Country of Emigration Again? Data Evidence and Public Responses». In South-North Migration of EU Citizens in Times of Crisis. Springer International Publishing, pp. 83-98.

Cortés Maisonave, A.; Moncó Rebollo, B. y Betrisey Nadali, D. (2015): Movilidad transnacional de jóvenes españoles y latinoamericanos: una comparación en contextos de crisis. Madrid, Centro Reina Sofía sobre Adolescencia y Juventud, FAD.

Daguet, F. (1995): Un siècle de démographie française: structure et évolution de la population de 1901 à 1993 (Vol. 47). Paris, INSEE.

Domingo i Valls, A. y Blanes, A. (2016): "La nueva emigración española». Panorama social, (23), pp. 157-178.

Domingo, A.; Sabater, A. y Ortega, E. (2014): «¿Migración neohispánica? El impacto de la crisis económica en la emigración española». Empiria, 29(1), pp. 39-66.

Domínguez-Mujica, J.; Díaz-Hernández, R. y Parreño-Castellano, J. (2016): «Migrating Abroad to Get Ahead: The Emigration of Young Spanish Adults During the Financial Crisis (2008-2013)». In Global Change and Human Mobility. Singapore, Springer, pp. 203-223.

Dreyfus-Armand, G. (2000): El exilio de los republicanos españoles en Francia: de la guerra civil a la muerte de Franco. Barcelona, Crítica.

Ehrenreich, B. y Hochschild, A. R. (eds.) (2002): Global Women: Nannies, Maids and Sex Workers in the New Economy. New York, Henry Holt and Company.

Eremenko, T.; El Qadim, N. y Steichen, E. (2017): «Southern Europeans in France: Invisible Migrants?». In South-North Migration of EU Citizens in Times of Crisis. Springer International Publishing, pp. 123-148.

Garrido, J.; Miyar, M. y Muñoz Comet, J. (2010): «La dinámica laboral de los inmigrantes en el cambio de fase del ciclo económico». Presupuesto y Gasto Público, 61, pp. 201-221.

Glick Schiller, N.; Basch, L. y Blanc-Szanton C. (eds.) (1992): Towards a Transnational Perspective on Migration: Race, Class, Ethnicity and Nationalism Reconsidered. New York, Academy of Sciences.

Glorius, B. (2017): «Study German to shape your future? - Motives for foreign language acquisition among Spaniards». In European Mobility in Times of Crisis: The New Context of European South-North Migration. Bielefeld, Verlag, pp. 105-131.

Glorius, B: Domínguez-MúJica, J. (eds.) (2017): European Mobility in Times of Crisis: The New Context of European South. Verlag, Bielefeld.

GonzÁlez-Ferrer, A. (2013): «La nueva emigración española». Zoom Político, 18.

Gropas, R. y Triandafyllidou, A. (2014): Survey report. Emigrating in times of crisis. Highlights and new data from an e-survey on high-skilled emigrants from Southern Europe and Ireland. Global Governance Program, European University Institute. Available online at: http:// globalgovernance 
programme. eui. eu/wp-content/uploads/2014/03/SURVEY-REPORTEmigrating-in-times-of-crisis. pdf (accessed: 2 April 2015).

Lafleur, J. M.; StaneK, M. y Veira, A. (2017): «South-North Labour Migration Within the Crisis-Affected European Union: New Patterns, New Contexts and New Challenges». In South-North Migration of EU Citizens in Times of Crisis. Springer International Publishing, pp. 193-214.

Levitt, P. y Schiller, N. G. (2006): «Perspectivas internacionales sobre migración». In, Portes, A. y De Wind, J. (coord.): Repensando las migraciones. Nuevas perspectivas teóricas y empíricas. México, Porrúa.

Lillo, N. (2004): La petite Espagne de la Plaine-Saint-Denis: 1900-1980. Paris: Autrement.

López-SALA, A. (2017): "The new emigration issue in the public and political debate in Spain»In Glorius, B. y Domínguez-Música: European Mobility in Times of Crisis: The New Context of European South-North Migration. Bielefeld, Verlag.

López-SALA, A. y Oso, L. (2015): «Inmigración en tiempos de crisis: dinámicas de movilidad emergentes y nuevos impactos sociales». Revista Migraciones, 37, Issn: 1138-5774, DOI: mig.i37.y2015.0019.

Moré Corral, P. (2015): «La organización social de los cuidados en Madrid y París: de la domesticidad a la profesionalización en la intersección género, clase y etnicidad». Tesis Doctoral, Universidad Complutense de Madrid (Programa Oficial de Doctorado en Migraciones Internacionales e Integración Social-Sociología).

Navarrete Moreno, L.; Cuenca García, C.; Díaz Catalán, C.; Díaz Chorne, L. y ZúÑaga, R. (2014): La emigración de los jóvenes españoles en el contexto de la crisis: Análisis y datos de un fenómeno difícil de cuantificar. Madrid, INJUVE-Observatorio de la Juventud en España.

Observatorio Permanente Andaluz de las Migraciones (OPAM) (2013): España, ¿país de emigración? La imagen de éxodo, a prueba de evidencia estadística. Tema OPAM no8, junio 2013. http://www.juntadeandalucia. es/justiciaeinterior/opam/sites/default/files/DOC/TemaOPAM_n8_Junio2013-WEB.pdf

Oso Casas, L. (2004): Españolas en París. Estrategias de ahorro y consumo en las migraciones internacionales. Barcelona, Edicions Bellaterra.

Oso, L. (dir.) (2008): Trans-ciudadanos: hijos de la emigración española en Francia. Madrid, Fundación Francisco Largo Caballero.

Oso, L. y Ribas-Mateos, N. (eds.) (2015): The International Handbook on Gender, Migration and Transnationalism: Global and Development Perspectives. Cheltenham, UK, Edward Elgar Publishing.

Oso, L.; SÁiz López, A. y Cortés, A. (2017): «Movilidades cruzadas» en un contexto de crisis: «Una propuesta teorica para el estudio de la movilidad geografica y social, con un enfoque de genero, transnacional e intergeneracional.» Monografico «Migraciones y movilidad social: escalando la jerarquia social en el espacio transnacional». Revista Española de Sociología, Volumen 26, numero 2, pp. 293-306. 
Pumares, P. (2017): «The changing migration projects of Spaniards in the UK». In Glorius, B. y Domínguez-Música: European Mobility in Times of Crisis: The New Context of European South-North Migration. Bielefeld, Verlag.

Romero Valiente, J. M. (2017): "Patrones y diferencias sociodemográficas en el registro estadístico de la emigración española actual». Estudios demográficos y urbanos, 32(1), pp. 163-197.

Rubio Ros, C. (2013): «Londres, tierra prometida. La emigración de jóvenes titulados universitarios catalanes a Londres». Perifèria: revista de recerca i formació en antropologia, 18(2), 0158-174.

SASSEN, S. (2003): «The feminisation of survival: alternative global circuits». In Morokvasic-Müller, M., Erel, U. y K. Shinozaki (eds.): Crossing Borders and Shifting Boundaries, Vol. I. Gender on the Move. Opladen, Leske+budrich, pp. 59-77.

Taboada-Leonetti, I. y Guillon, M. (1987) : Les immigrés des beaux quartiers. La communauté espagnole dans les XVI. Paris, CIEMI, L'Harmattan.

TRuONG T. (1996): "Gender, International Migration and Social Reproduction: Implications for Theory, Policy Research and Networking». Asian and Pacific Migration Journal, 5 (1), pp. 27-52.

Tur, B. (2014): "L’immigration espagnole à Paris dans les années 1960: discours, représentations et stéréotypes». Thèse de Doctorat dirigée par Marie-Claude Chaput, Université Paris Ouest Nanterre La Défense.

Vertovec, S. (2004): Trends and Impacts of Migrant Transnationalism. Oxford, University of Oxford, Center on Migration, Policy and Society, Working Paper $\mathrm{N}^{\mathrm{o}}$ 3, WP-04-03. 
